\title{
Hair Regrowth and Increased Hair Tensile Strength Using the HairMax LaserComb for Low-Level Laser Therapy
}

\author{
JOHN L. SATINO and MICHAEL MARKOU, D.O.
}

\begin{abstract}
The authors wished to confirm the efficacy of low level laser therapy (LLLT) using a HairMax LaserComb for the stimulation of hair growth and also to determine what effect LLLT with this device had on the tensile strength of hair. Thirty-five patients, 28 males and $7 \mathrm{fe}-$ males, with androgenetic alopecia (AGA) underwent treatment for a six-month period. Both the hair counts and tensile strength of the hair were affected very beneficially in both sexes in the temporal and vertex regions, with the males and vertex areas showing the most improvement.
\end{abstract}

\section{INTRODUCTION}

A LTHOUgh LOW-LEVEL LaSer therapy (LLLT), the therapeutic application of low-energy lasers to medicine, has been used for photobiostimulation for more than thirty years now, in the past it has primarily been used to accelerate the healing of burns or wounds, or alternatively, to ease or relieve pain. Furthermore, LLLT has gained credibility and common usage in some parts of the world, such as Japan, the Scandinavian countries, and Australia, while in other parts of the world, such as North America, a lack of recognition of its efficacy has remained.

Even though there are more than 2,500 papers related to LLLT in the scientific literature, ${ }^{(1)}$ only one printed reference, Professor Pekka Pontinen's text, was found which actually discussed the use of LLLT "to stimulate hair growth."(2) Even in this source, the information was limited to one paragraph, which refers to one paper given in Sorrento in 1982 which reported increased hair growth after LLLT in animals, ${ }^{(3)}$ and a foreign language publication in 1983 which reported favorable results with LLLT in the treatment of Alopecia areata. $^{(4)}$ The authors heard about Dr. Martin Unger's paper in Puerto Vallarta, Mexico, discussing the use of LLLT for hair biostimulation, ${ }^{(5)}$ and around this same time period, the fall of 2001, became interested in the HairMax LaserComb (Lexington International, Boca Raton, FL), secondary to several anecdotal reports that they had heard about this device. It was at this time that the authors decided to carry out their own study to determine whether the HairMax LaserComb was effective with regard to stimulating hair growth. The authors also wished to determine what affect LLLT had on the tensile strength of hair and undertook to determine this during the same study.

\section{MATERIALS AND METHODS}

The HairMax LaserComb (Figs. 1, 2) was selected as the LLLT device for many important reasons. As noted above, the authors had heard several favorable anecdotal reports about its ef- 


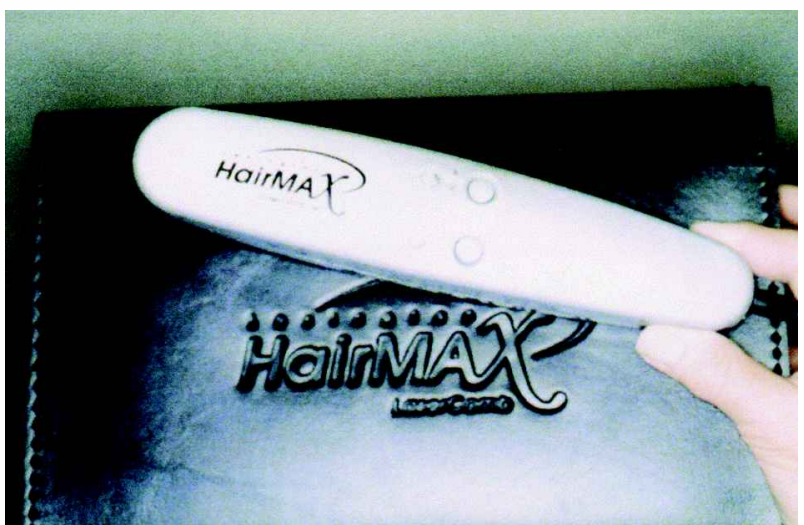

FIG. 1. Dorsal view of the HairMax LaserComb and its leather storage case.

ficacy. Secondly, the cost of the device was affordable (www.lasercomb.net), and thirdly, the device was simple enough for the patient to use at home, avoiding repeated visits to the clinic. The facts that the device was completely safe, and that no adverse side effects had ever occurred, were also important considerations. In addition, the comblike teeth of the device separates the hair so that the nine laser beams emitted can easily reach the scalp without absorption or interference from existing hair, and the laser beams themselves are visible light energy

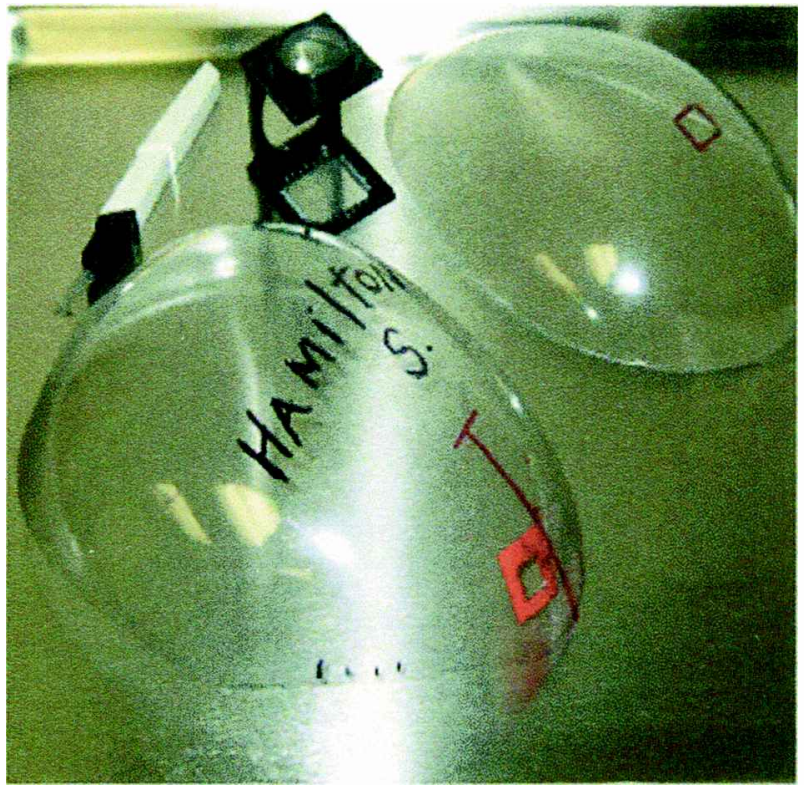

FIG. 3. Clear acrylic head mold with the one-square-centimeter opening noted in the vertex area, and outlined in red.

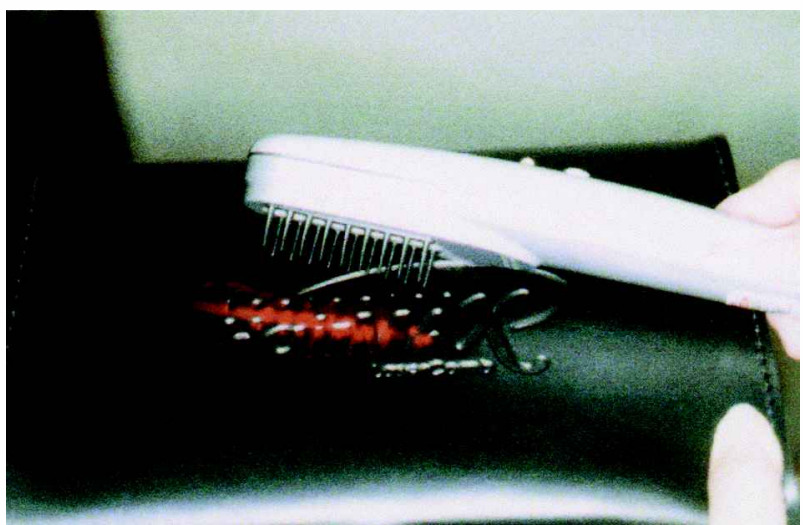

FIG. 2. Lateral view of the HairMax LaserComb, demonstrating the nine laser beams on the case and the comblike teeth extending from its ventral surface.

allowing the patients to see for themselves that the device is operating.

In total, 35 patients with androgenetic alopecia (AGA) were involved in the study, of which 28 were males, aged 28 to 72 , and 7 were females, aged 46 to 76 . Each patient was given a HairMax LaserComb to use at home for six full months and was instructed to comb his/her entire scalp hair slowly (advancing one-quarter of an inch per second) for five to ten minutes every other day. The treatment was to be carried out when the hair and scalp were clean and the hair was dry. A hair count in the greatest area of alopecia and a determination of the tensile strength of the hair was carried out before treatment was started and again after six months of treatment.

As each patient was troubled by AGA to start with, the authors did not want to clip additional

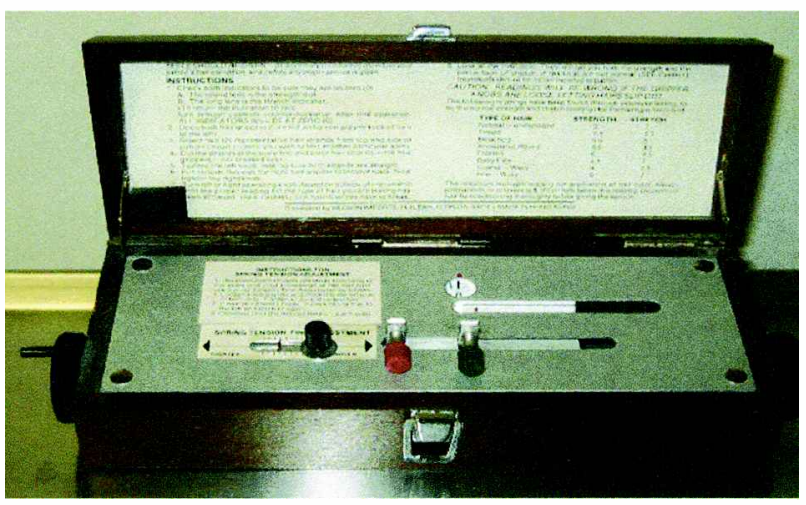

FIG. 4. A frontal view of the VIP HairOScope used for measuring the hair tensile strength. 
hair for the hair counts. Accordingly, they created a clear acrylic mold of each patient's head, with the front of the mold positioned at the hairline, and a one-centimeter square removed from the mold in the area of greatest alopecia in either the temporal or vertex region (Fig. 3). For the hair count, the hairs within the one square centimeter space were pulled through the opening, and then counted using a surgical skin hook and a lens with five times magnification. Hair counts were carried out by both authors to confirm the accuracy of the data.

To test the tensile strength of the hair before treatment and after six months of treatment, three typical terminal hairs were removed from the one square centimeter area and a VIP HairOScope (Belson Imports, Hialeah, FL) used to determine the tensile strength (Fig. 4).

Table 1. HairMax LaserComb Hair Count Data

\begin{tabular}{|c|c|c|c|c|c|c|c|c|}
\hline \multirow[b]{2}{*}{ Number } & \multirow[b]{2}{*}{ Patient } & \multirow[b]{2}{*}{ Age } & \multirow[b]{2}{*}{ Sex } & \multirow[b]{2}{*}{ Area } & \multicolumn{2}{|c|}{ Hair Count } & \multirow[b]{2}{*}{ Difference } & \multirow[b]{2}{*}{ Change(\%) } \\
\hline & & & & & Baseline & 6 months after & & \\
\hline 1 & $\mathrm{RC}$ & 47 & $\mathrm{M}$ & $\mathrm{T}$ & 23 & 45 & 22 & 95.7 \\
\hline 2 & $\mathrm{CP}$ & 34 & $\mathrm{M}$ & $\mathrm{T}$ & 33 & 51 & 18 & 54.5 \\
\hline 3 & DL & 28 & $\mathrm{M}$ & $\mathrm{T}$ & 22 & 31 & 9 & 40.9 \\
\hline 4 & $\mathrm{SH}$ & 56 & M & $\mathrm{T}$ & 6 & 11 & 5 & 83.3 \\
\hline 5 & WG & 35 & $\mathrm{M}$ & $\mathrm{T}$ & 16 & 28 & 12 & 75.0 \\
\hline 6 & JC & 29 & $\mathrm{M}$ & $\mathrm{T}$ & 38 & 56 & 18 & 47.4 \\
\hline 7 & TM & 34 & $\mathrm{M}$ & $\mathrm{T}$ & 12 & 46 & 34 & 283.3 \\
\hline 8 & $\mathrm{JH}$ & 51 & $\mathrm{M}$ & $\mathrm{T}$ & 18 & 27 & 9 & 50.0 \\
\hline 9 & LM & 63 & $\mathrm{M}$ & $\mathrm{T}$ & 16 & 16 & 0 & 0.0 \\
\hline 10 & JT & 29 & $\mathrm{M}$ & $\mathrm{T}$ & 15 & 23 & 8 & 53.3 \\
\hline \multirow[t]{2}{*}{11} & AT & 36 & $\mathrm{M}$ & $\mathrm{T}$ & 28 & 37 & 9 & 32.1 \\
\hline & Average (T) & 40.2 & & & 20.6 & 33.7 & 13.1 & 74.1 \\
\hline 12 & $\mathrm{DB}$ & 55 & $\mathrm{M}$ & $\mathrm{V}$ & 8 & 22 & 14 & 175.0 \\
\hline 13 & RK & 37 & M & V & 36 & 41 & 5 & 13.9 \\
\hline 14 & PP & 29 & $\mathrm{M}$ & $\mathrm{V}$ & 22 & 61 & 39 & 177.3 \\
\hline 15 & EL & 34 & $\mathrm{M}$ & $\mathrm{V}$ & 19 & 36 & 17 & 89.5 \\
\hline 16 & $\mathrm{JI}$ & 51 & $\mathrm{M}$ & V & 18 & 27 & 9 & 50.0 \\
\hline 17 & BG & 48 & $\mathrm{M}$ & $\mathrm{V}$ & 14 & 64 & 50 & 357.1 \\
\hline 18 & SA & 59 & M & $\mathrm{V}$ & 12 & 23 & 11 & 91.7 \\
\hline 19 & $\mathrm{DB}$ & 29 & $\mathrm{M}$ & V & 18 & 26 & 8 & 44.4 \\
\hline 20 & EW & 38 & $\mathrm{M}$ & $\mathrm{V}$ & 22 & 28 & 6 & 27.3 \\
\hline 21 & JS & 56 & M & V & 18 & 31 & 13 & 72.2 \\
\hline 22 & MB & 35 & $\mathrm{M}$ & V & 22 & 39 & 17 & 77.3 \\
\hline 23 & PL & 46 & $\mathrm{M}$ & $\mathrm{V}$ & 12 & 23 & 11 & 91.7 \\
\hline 24 & JL & 72 & $\mathrm{M}$ & V & 12 & 33 & 21 & 175.0 \\
\hline 25 & CR & 42 & $\mathrm{M}$ & $\mathrm{V}$ & 12 & 23 & 11 & 91.7 \\
\hline 26 & $\mathrm{PH}$ & 60 & $\mathrm{M}$ & $\mathrm{V}$ & 12 & 27 & 15 & 125.0 \\
\hline 27 & RH & 42 & $\mathrm{M}$ & V & 24 & 38 & 14 & 58.3 \\
\hline \multirow[t]{3}{*}{28} & JB & 30 & $\mathrm{M}$ & V & 4 & 17 & 13 & 325.0 \\
\hline & Average (V) & 44.9 & & & 16.8 & 32.9 & 16.1 & 120.1 \\
\hline & verage $(\mathrm{V}+\mathrm{T})$ & 43.1 & & & 18.2 & 33.2 & 15.0 & 102.7 \\
\hline 29 & $\mathrm{JL}$ & 56 & $\mathrm{~F}$ & $\mathrm{~T}$ & 32 & 51 & 19 & 59.4 \\
\hline 30 & $\mathrm{FP}$ & 66 & $\mathrm{~F}$ & $\mathrm{~T}$ & 19 & 27 & 8 & 42.1 \\
\hline 31 & EL & 71 & $\mathrm{~F}$ & $\mathrm{~T}$ & 22 & 29 & 7 & 31.8 \\
\hline \multirow[t]{2}{*}{32} & LW & 46 & $\mathrm{~F}$ & $\mathrm{~T}$ & 8 & 15 & 7 & 87.5 \\
\hline & Average (T) & 59.8 & & & 20.3 & 30.5 & 10.3 & 55.2 \\
\hline 33 & $\mathrm{NC}$ & 64 & $\mathrm{~F}$ & $\mathrm{~V}$ & 19 & 29 & 10 & 52.6 \\
\hline 34 & PJ & 76 & $\mathrm{~F}$ & V & 18 & 36 & 18 & 100.0 \\
\hline \multirow{6}{*}{ Ave } & RM & 49 & $\mathrm{~F}$ & $\mathrm{~V}$ & 19 & 27 & 8 & 42.1 \\
\hline & Average (V) & 63.0 & & & 18.7 & 30.7 & 12.0 & 64.9 \\
\hline & verage $(T+V)$ & 59.8 & & & 20.3 & 30.5 & 10.3 & 55.2 \\
\hline & age $(\mathrm{T}, \mathrm{M}+\mathrm{F})$ & 45.4 & & & 20.5 & 32.9 & 12.3 & 69.1 \\
\hline & age $(V, M+F)$ & 47.6 & & & 17.1 & 32.6 & 15.5 & 111.9 \\
\hline & $(\mathrm{T}+\mathrm{V}, \mathrm{M}+\mathrm{F})$ & 46.7 & & & 18.5 & 32.7 & 14.1 & 93.5 \\
\hline
\end{tabular}

$\mathrm{M}$, male; $\mathrm{F}$, female; $\mathrm{T}$, temporal; $\mathrm{V}$, vertex. 


\section{RESULTS}

The scientific data for the hair counts is demonstrated in Table 1, and the data for the tensile strength of the hair recorded in Table 2. One-third of the patients did report some temporary slightly increased hair shedding during the first one or two months of treatment, but after two months, this no longer occurred.

In summary, Table 1 shows that the hair counts increased in the temporal area an average of $55.2 \%$ in women, $74.1 \%$ in men, and $69.1 \%$ for all patients. In the vertex area, the corresponding percentages were $64.9 \%$ for women, $120.1 \%$ for men, and $111.9 \%$ for all patients. There was a hair count increase of $93.5 \%$ when all temporal and vertex patients were combined. In general, males and the vertex area did the best, but both sexes and all areas did demonstrate significant improvement.

Table 2. HairMax LaserComb Hair Tensile Strength Data

\begin{tabular}{|c|c|c|c|c|c|c|c|c|}
\hline \multirow[b]{2}{*}{ Number } & \multirow[b]{2}{*}{ Patient } & \multirow[b]{2}{*}{ Age } & \multirow[b]{2}{*}{ Sex } & \multirow[b]{2}{*}{ Area } & \multicolumn{2}{|c|}{ Hair tensile } & \multirow[b]{2}{*}{ Difference } & \multirow[b]{2}{*}{ Change(\%) } \\
\hline & & & & & Baseline & 6 months after & & \\
\hline 1 & $\mathrm{RC}$ & 47 & M & $\mathrm{T}$ & 4.5 & 5.9 & 1.4 & 31.1 \\
\hline 2 & $\mathrm{CP}$ & 34 & M & $\mathrm{T}$ & 3.8 & 6.1 & 2.3 & 60.5 \\
\hline 3 & DL & 28 & M & $\mathrm{T}$ & 3.7 & 4.2 & 0.5 & 13.5 \\
\hline 4 & $\mathrm{SH}$ & 56 & M & $\mathrm{T}$ & 2.1 & 3.5 & 1.4 & 66.7 \\
\hline 5 & WG & 35 & M & $\mathrm{T}$ & 2.3 & 3.6 & 1.3 & 56.5 \\
\hline 6 & $\mathrm{JC}$ & 29 & M & $\mathrm{T}$ & 2.4 & 4.1 & 1.7 & 70.8 \\
\hline 7 & TM & 34 & $\mathrm{M}$ & $\mathrm{T}$ & 1.2 & 5.2 & 4.0 & 333.3 \\
\hline 8 & $\mathrm{JH}$ & 51 & M & $\mathrm{T}$ & 5.5 & 6.3 & 0.8 & 14.5 \\
\hline 9 & LM & 63 & M & $\mathrm{T}$ & 2.4 & 2.9 & 0.5 & 20.8 \\
\hline 10 & JT & 29 & M & $\mathrm{T}$ & 4.2 & 4.9 & 0.7 & 16.7 \\
\hline \multirow{2}{*}{11} & AT & 36 & \multirow[t]{2}{*}{$\mathrm{M}$} & \multirow[t]{2}{*}{$\mathrm{T}$} & 4.6 & 5.7 & 1.1 & 23.9 \\
\hline & Average (T) & 40.2 & & & 3.3 & 4.8 & 1.4 & 64.4 \\
\hline 12 & DB & 55 & $\mathrm{M}$ & V & 1.6 & 3.7 & 2.1 & 131.3 \\
\hline 13 & RK & 37 & M & V & 4.0 & 5.8 & 1.8 & 45.0 \\
\hline 14 & PP & 29 & $\mathrm{M}$ & V & 2.9 & 5.8 & 2.9 & 100.0 \\
\hline 15 & EL & 34 & M & V & 4.1 & 5.4 & 1.3 & 31.7 \\
\hline 16 & JI & 51 & M & V & 1.9 & 3.1 & 1.2 & 63.2 \\
\hline 17 & BG & 48 & M & V & 3.5 & 4.7 & 1.2 & 34.3 \\
\hline 18 & SA & 59 & M & $\mathrm{V}$ & 2.3 & 5.0 & 2.7 & 117.4 \\
\hline 19 & DB & 29 & M & V & too short & & $\mathrm{N} / \mathrm{A}$ & $\mathrm{N} / \mathrm{A}$ \\
\hline 20 & EW & 38 & M & V & 2.9 & 3.1 & 0.2 & 6.9 \\
\hline 21 & JS & 56 & M & V & 1.1 & 3.1 & 2.0 & 181.8 \\
\hline 22 & MB & 35 & M & V & 0.8 & 2.3 & 1.5 & 187.5 \\
\hline 23 & PL & 46 & $\mathrm{M}$ & V & 1.7 & 4.0 & 2.3 & 135.3 \\
\hline 24 & JL & 72 & M & V & 2.9 & 4.6 & 1.7 & 58.6 \\
\hline 25 & CR & 42 & M & V & 2.8 & 4.3 & 1.5 & 53.6 \\
\hline 26 & $\mathrm{PH}$ & 60 & M & V & 2.4 & 4.3 & 1.9 & 79.2 \\
\hline 27 & $\mathrm{RH}$ & 42 & M & V & 1.3 & 3.5 & 2.2 & 169.2 \\
\hline \multirow[t]{3}{*}{28} & JB & 30 & \multirow[t]{3}{*}{$\mathrm{M}$} & \multirow[t]{3}{*}{$\mathrm{V}$} & 3.8 & 5.1 & 1.3 & 34.2 \\
\hline & Average (V) & 44.9 & & & 2.5 & 4.2 & 1.7 & 89.3 \\
\hline & verage $(V+T)$ & 43.1 & & & 2.8 & 4.4 & 1.6 & 79.5 \\
\hline 29 & $\mathrm{JL}$ & 56 & $\mathrm{~F}$ & $\mathrm{~T}$ & 2.0 & 4.6 & 2.6 & 130.0 \\
\hline 30 & FP & 66 & F & $\mathrm{T}$ & 3.2 & 3.8 & 0.6 & 18.8 \\
\hline 31 & EL & 71 & F & $\mathrm{T}$ & 2.2 & 4.0 & 1.8 & 81.8 \\
\hline \multirow[t]{2}{*}{32} & LW & 46 & \multirow[t]{2}{*}{$\mathrm{F}$} & \multirow[t]{2}{*}{$\mathrm{T}$} & 2.7 & 5.4 & 2.7 & 100.0 \\
\hline & Average (T) & 59.8 & & & 2.5 & 4.5 & 1.9 & 82.6 \\
\hline 33 & $\mathrm{NC}$ & 64 & $\mathrm{~F}$ & V & 1.7 & 2.9 & 1.2 & 70.6 \\
\hline 34 & PJ & 76 & $\mathrm{~F}$ & V & 2.1 & 3.4 & 1.3 & 61.9 \\
\hline \multirow{6}{*}{$\begin{array}{r}\text { Ave } \\
\text { Ave } \\
\text { Averao }\end{array}$} & RM & 49 & \multirow[t]{6}{*}{$\mathrm{F}$} & \multirow[t]{6}{*}{ V } & 2.1 & 3.8 & 1.7 & 81.0 \\
\hline & Average (V) & 63.0 & & & 2.0 & 3.4 & 1.4 & 71.1 \\
\hline & verage $(T+V)$ & 59.8 & & & 2.5 & 4.5 & 1.9 & 82.6 \\
\hline & age $(\mathrm{T}, \mathrm{M}+\mathrm{F})$ & 45.4 & & & 3.1 & 4.7 & 1.6 & 69.3 \\
\hline & age $(\mathrm{V}, \mathrm{M}+\mathrm{F})$ & 47.6 & & & 2.4 & 4.1 & 1.7 & 86.4 \\
\hline & $(T+V, M+F)$ & 46.7 & & & 2.7 & 4.4 & 1.6 & 78.9 \\
\hline
\end{tabular}

$\mathrm{M}$, male; $\mathrm{F}$, female; $\mathrm{T}$, temporal; $\mathrm{V}$, vertex. 
Similarly, in Table 2, the hair tensile strength increased in the temporal area $82.6 \%$ in women, $64.4 \%$ in men, and $69.3 \%$ in both sexes. In the vertex area, the percentages were $71.1 \%$ for women, $89.3 \%$ for men, and $86.4 \%$ for both sexes. The hair tensile strength was increased $78.9 \%$ when all temporal and vertex patients were considered. There was greater improvement in the vertex area in males, but more improvement in the temporal area in females. Both sexes and all areas did benefit significantly.

\section{DISCUSSION}

In general, the results far exceeded the expectations of the authors, and they were pleased to be able to document the benefits that LLLT with the HairMax LaserComb can achieve for both men and women in both the temporal and vertex regions. Although there were four times as many men as women patients in the study, each sex did demonstrate significant benefits from the LLLT.

The mechanism or mechanisms of action of LLLT are unknown with regard to the stimulation of hair growth or how the hair tensile strength is increased so greatly. From wound healing studies, it is known that LLLT causes an increase in the microcirculation of tissue and a reduction in inflammation..$^{(2)}$ The amount of cellular energy in the form of adenosine triphosphatase (ATP) is also increased following LLLT. ${ }^{(2)}$ Perhaps one or more of these beneficial effects are responsible for the results that we were able to achieve. The authors hypothesized that the early temporary hair shedding experienced by some patients was most likely related to an accelerated hair cycle in general. Obviously, more research is required if we are to fully understand the scientific findings noted in this paper.

\section{CONCLUSION}

LLLT with the HairMax LaserComb is an effective treatment for stimulating hair growth and increasing the tensile strength of hair in both sexes in both the temporal and vertex regions. In the authors' opinion, LLLT should be given serious consideration as an option in the treatment of AGA in view of its safety, ease of patient home administration, and the benefits documented in this study.

\section{REFERENCES}

1. LaserWorld LLLT Internet Guide (http://www.laser.nu/).

2. Pontinen, P.: Low Level Laser Therapy as a Medical Treatment Modality. Art Urpo, Ltd., Publishers, 1992, pp 99-101.

3. Trelles, M., and Mayayo, E.: The Growth of Hair under Influence of the He-Ne Laser Beam: Histological Study. Sorrento. World Congress of Laser-Therapy, 1982.

4. Trelles, M., Mayayo, E., Schmidt, C., Igllesias, J., and Barber, J.: Laser Para la Salud y la Estetica. Etecnes, 2nd. edition, 1983, pp 98-107.

5. Unger, M.: Low Level Laser Therapy (LLLT) for Hair Biostimulation, $9^{\text {th }}$ Annual Meeting of the International Society of Hair Restoration Surgery, Puerto Vallarta,

Address reprint requests to: John L. Satino Clinic Director \& Laser Safety Officer

The Laser Hair and Scalp Clinic 13555 Automobile Boulevard, No. 110

Clearwater, FL 33762

E-mail: hslaser@sisna.com 